\title{
Crigler Najjar Syndrome Type 2: a Case of Unexplained Jaundice in an Adult
}

\author{
MA Rahman ${ }^{1}$, MMSU Islam², N Tasnim³
}

\begin{abstract}
:
Crigler-Najjar Syndrome (CNS) type 2 is a rare genetic disorder which is characterized by non-hemolytic unconjugated hyperbilirubinaemia. It is caused by defect in bilirubin conjugation due to complete or partial deficiency of uridine 5'-diphosphate-glucuronosyltransferase (UGT). Affected individuals are usually asymptomatic apart from the jaundice and investigations reveal isolated indirect hyperbilirubinemia. Genetic testing of the UGT1A1 gene for mutations is the definitive diagnostic tool which is not available everywhere. It can be alternatively diagnosed by evaluating the response to phenobarbitone in terms of fall in bilirubin level. Here, we report one such rare case.
\end{abstract}

Key words: Isolated indirect hyperbilirubinemia, Gilbert's syndrome, Crigler Najjar Syndrome, Phenobarbitone.

\section{Case Report :}

A 49 years old, male, unmarried, muslim, nondiabetic, hypertensive village doctor came to hospital with the complaints of persistent yellowish discoloration of eyes, skin since childhood which is more marked after exercise and fasting for a prolong period. This was not associated with fever, abdominal pain, anorexia, nausea, vomiting, weight loss, itching of whole body, pale coloured stool or dark urine. There was also no history of neuropsychiatric complaints, blood transfusion, chronic drug exposure or any addiction. He also complained of several episodes of hiccup for the last 30 years which usually started when there was increased yellow discoloration of his eyes and it resolved within 3 to 4 days. He was born of a nonconsanguineous marriage. One of his 3 brothers has similar type of illness since childhood.

He was hypertensive for the last 5 years \& took losartan $25 \mathrm{mg}$ regularly. His bowel \& bladder habit was normal.

On examination, the patient was icteric $(++)$. Anaemia was absent. There was no organomegaly,

1. Dr. Mohammad Ashiqur Rahman, MBBS, MRCP (UK), Registrar, Department of Medicine, Faridpur Medical College Hospital.

2. Dr. M.M. Shahin-Ul-Islam, MBBS, FCPS (Medicine), MD (Gastroenterology), Associate Professor (CC), Department of Gastroenterology, Faridpur Medical College.

3. Dr. Nazifa Tasnim, MBBS, Medical Officer, Upazila Health Complex, Sonaimuri, Noakhali.

\footnotetext{
Address of correspondence :

Dr. Mohammad Ashiqur Rahman, MBBS, MRCP (UK), Registrar, Department of Medicine, Faridpur Medical College Hospital.

Phone: +8801673781469, E-mail: ashique49@yahoo.com
}

lymphadenopathy or abdominal tenderness, no scratch mark on skin. Pulse was $76 \mathrm{~b} / \mathrm{min}$, and BP $130 / 80 \mathrm{~mm}$ $\mathrm{Hg}$. Other systemic examinations revealed no abnormality.

Investigations showed normal blood count with normal findings on peripheral blood film. He had done serum bilirubin level several times which showed persistent indirect hyperbilirubinaemia. The highest $\mathrm{S}$. biliurubin was $18.0 \mathrm{mg} / \mathrm{dl}$ where level of indirect bilirubin was $17.5 \mathrm{mg} / \mathrm{dl}$. SGPT, SGOT, PT, S. albumin, and USG of Hepatobiliary system were normal. Direct and indirect Coomb's test was negative. Reticulocyte count was $2 \%$ and LDH was also within normal limit. Endoscopy of upper GIT was also normal. Blood test for hepatitis A, $\mathrm{B}, \mathrm{C}, \mathrm{E}$ and HIV were negative. Other biochemical parameters including renal function, serum electrolytes were within normal limit.

In view of the long standing jaundice and isolated indirect hyperbilirubinaemia he was suspected as a case of Crigler Najjar Syndrome (CNS) Type 2. As genetic mutation analysis for CNS is not available in Bangladesh we directly went for treatment and so he was given oral phenobarbitone $60 \mathrm{mg}$ twice daily and advised him for follow up visit after 2 weeks. Follow up visit showed sharply decreased serum bilirubin level to $8.25 \mathrm{mg} / \mathrm{dl}$. His phenobarbitone dose was increased to $60 \mathrm{mg}$ thrice daily. After 1 month, follow up visit showed further decreased serum bilirubin to $4.6 \mathrm{mg} / \mathrm{dl}$ where indirect bilirubin level was $4.2 \mathrm{mg} / \mathrm{dl}$. He did not experienc any episode of hiccup within that 1 month. Responsiveness of indirect bilirubinaemia after phenobarbitone therapy confirmed the diagnosis of 
CNS type 2. His brother also took same therapy which showed improvement of serum bilirubin level. The patient was advised for genetic counseling.

\section{Discussion :}

Crigler-Najjar Syndrome (CNS) is a rare genetic disorder which is characterized by abnormalities in bilirubin metabolism and evident by persistent increase of unconjugated bilirubin. It has two types, type 1 and type 2. The key pathogenesis is mutation in the UGTA1 gene which contains instructions for encoding a liver enzyme called Uridine disphosphate glucuronosyltransferase-1 (UGT1A1) ${ }^{1}$. This enzyme is required for the conjugation of bilirubin to excrete from the body. In type 1 CNS there is complete absence of the enzyme and in type 2 there is partial absence of the enzyme. So, Type 1 is more severe form and newborn rarely survive beyond infancy due to accumulation of excess bilirubin in the brain. Type 2 is less severe and has better prognosis.

Crigler-Najjar Syndrome is mostly autosomal recessive disorder but variation may occur in the inheritance of CNS type $2^{2}$. Both males and females may be affected by CNS equally. The incidence is approximately 1 in $750,000-1,000,000$ in the general population ${ }^{3}$.

The other cause of congenital indirect hyperbilirubinaemia is Gilbert syndrome. In Gilbert syndrome serum bilirubin level rarely exceeds 6 $\mathrm{mg} / \mathrm{dl}^{4}$. But in type 2 CNS serum bilirubin is usually up to $20 \mathrm{mg} / \mathrm{dl}$ or even more during intercurrent illness ${ }^{5}$.

The symptoms of Crigler-Najjar Syndrome type 1 is jaundice which is severe, persistent and starts shortly after birth. Infants develop kernicterus within first month of life and it causes death of the infant. Rarely kernicterus may not develop until later childhood or early adulthood ${ }^{6}$. Type 2 is milder form of CNS than type 1 . There is also persistent jaundice which is marked during intercurrent illness, prolonged fasting or by general anesthesia. Some people have not been diagnosed until adulthood. Kernicterus is rare in type 2 CNS.

So, the first clue of CNS is persistent indirect hyperbilirubinaemia. To diagnose CNS we need to exclude hemolytic anaemia as well. To confirm the diagnosis molecular genetic testing is required which can detect mutations in the UGT1A1 gene that causes this disease. But it requires highly specialized laboratories which is not available everywhere.

To distinguish Crigler-Najjar syndrome type 1, type 2 and Gilbert syndrome the most reasonable approach is phenobarbitone trial. The administration of phenobarbital, a barbiturate, reduces blood bilirubin levels in individuals affected with Crigler-Najjar syndrome type 2 and Gilbert syndrome, but is ineffective for those with Crigler-Najjar syndrome type 1. In Gilbert's, after administration of phenobarbitone, the bilirubin levels normalize completely. In CNS type 2 the fall in bilirubin levels is usually more than 30 percent, but the levels never normalize. In CNS type 1, the fall is almost nil. The response in CNS type 2 with phenobarbitone is due to induction of the already present residual $10 \%-30 \%$ of (UGTA) enzyme activity required for bilirubin conjugation. Therefore, failure to respond to this medication is an important point in differential diagnostic purposes ${ }^{6}$.

Treatment of CNS is directed towards lowering unconjugated bilirubin level. The mainstay treatment for CNS type 1 is aggressive phototherapy to prevent development of kernicterus during the first few months of life. CNS type 2 is milder and responds very well to phenobarbital therapy and lifelong treatment is advised $^{7}$

The dose of phenobarbitone is $3-5 \mathrm{mg} / \mathrm{kg} /$ day titrated preferably to $60-180 \mathrm{mg} /$ day in single or divided doses $^{8}$. During pregnancy the dose is reduced further (30- $60 \mathrm{mg} /$ day) to avoid its teratogenic side effects. The response is seen within two to three weeks. An alternate medication is clofibrate $(2 \mathrm{~g} /$ day in divided doses), which has similar effect of phenobarbitone but it is contraindicated in pregnancy ${ }^{9}$. In addition, calcium supplementation has also been found to increase the gut excretion of bilirubin ${ }^{10}$. In some instances, during an episode of a hyperbilirubinemic crisis, patients with CNS type 2 may require phototherapy or plasmapheresis. Newer therapeutic modalities such as hepatocyte transplantation, enzyme replacement therapy (ERT) and gene therapy have not been used for CNS type 2 till date as the affected patients respond well on oral phenobarbitone only. Genetic counseling is recommended for the affected individuals and their families. Psychological support for the entire family is essential as well.

In our case, the 49 years old patient has history of jaundice from his childhood and his blood result showed persistently raised indirect hyperbilirubinaemia. Hemolysis was excluded by doing other blood tests. As there was no facility of doing the genetic testing to identify mutations of UGT1A1 gene we tried phenobarbitone trial to see the response. After adminstration of phenobarbitone his blood bilirubin level sharply declined within next few weeks from 18 $\mathrm{mg} / \mathrm{dl}$ to $4.6 \mathrm{mg} / \mathrm{dl}$ which alternatively confirms the diagnosis of CNS type 2 . 


\section{Conclusion:}

Though Crigler-Najjar Syndrome (CNS) type 2 is a rare genetic disorder, yet high level of clinical suspicion should be raised for it when a patient has persistent unexplained jaundice and blood report shows non hemolytic unconjugated hyperbilirubinaemia.

\section{References:}

1. Sappal BS, Ghosh SS, Shneider B, Kadakol A,Chowdhury JR, Chowdhury NR. A novel intronic mutation results in the use of a cryptic splice acceptor site within the coding region of UGT1A1, causing Crigler-Najjar syndrome type I. Mol Genet Metab. 2002; $75: 134-42$.

2. Chaudhary R, Maheshwari A, Deepmala D, Tapparwal V. A rare case of Crigler-Najjar syndrome type II with pregnancy. Int $\mathrm{J}$ Reprod Contracept Obstet Gynecol. 2014;3(1):261-62.

3. Crigler-Najjar Syndrome - NORD (National Organization for Rare Disorders).(2008). NORD (National Organization for Rare Disorders). Retrieved 20 July 2016, from http://rarediseases.org/rare-diseases/crigler-najjar-syndrome/

4. Blueger AF, Krupnikova EZ, Sondore VY, Semushina EP. Study of the etiology and pathogenesis of low grade nonhemolytic unconjugated hyperbilirubinemia (Gilbert's disease) Acta Hepatogastroenterol (Stuttg) 1977;24:140.

5. Pratt D, Kaplan M. Evaluation of abnormal liver-enzyme results in asymptomatic patients. New England Journal of Medicine. 2000;342(17):1266-71

6. Van der Veere CN, Sinaasappel M, McDonagh AF, Rosenthal P, Labrune P, Odiévre M, et al. Current therapy for Crigler-Najjar syndrome type 1: Report of a world registry. Hepatology. 1996;24(2):311-15.

7. Nair KM, Lohse P, Nampoothiri S. Crigler-Najjar syndrome type 2: Novel UGT1A1 mutation. Indian Journal of Human Genetics. 2012;18(2):233-34.

8. Ranjan P, Kohli S, Saxena R, Thakur S. Mutation analysis in Crigler-Najjar Syndrome type ii-case report and literature review. Journal of Clinical and Experimental Hepatology. 2011;1(3):204-06

9. Passuello V, Puhl AG, Wirth S, Steiner E, Skala C, Koelbl H, et al. Pregnancy outcome in maternal Crigler-Najjar syndrome type II: a case report and systematic review of the literature. Fetal DiagnTher. 2009;26:121-26

10. Pett S, Mowat AP. Crigler-Najjar syndrome types I and II. Clinical experience-King's College Hospital 1972-1978. Phenobarbitone, phototherapy and liver transplantation. Mol Aspects Med. 1987;9(5):473-82. 